\title{
IMMUNE-MEDIATED NECROTIZING MYOPATHY: AN IMPORTANT DIFFERENTIAL DIAGNOSIS OF MUSCLE WEAKNESS
}

Camila Aguiar Lomônaco ${ }^{1, \star}$, Dayani Regina de Barros Freitas dos Santos ${ }^{1}$, Nelson Araújo Silva Filho¹, Carla Oliveira Monteiro da Silva², Carolina Arribada Rebello²

1.Hospital Central da Aeronáutica, Rio de Janeiro (RJ), Brazil.; 2.Hospital de Força Aérea do Galeão, Rio de Janeiro (RJ), Brazil.

*Corresponding author: camila.lomonaco@hotmail.com

\section{BACKGROUND}

Immune-mediated necrotizing myopathy (IMNM) is a type of autoimmune myopathy characterized by relatively severe proximal weakness, elevated muscle enzymes (creatine kinase, $\mathrm{CPK},>10.000$ ), presence of specific antibodies and little or none inflammatory infiltrate on muscle biopsy, usually associated to the use of statins. Literature review suggests the frequency around 2 or 3 cases in each 100,000 patients.

\section{CASE REPORT}

A 64-year-old female patient, with hypertension and diabetes, started proximal and symmetrical muscle weakness in all four limbs in July 2020 presenting substantial raising of muscle enzymes ( $C P K>10,000$ ). Among other medicines, the patient used statin (atorvastatin) in regular to control comorbidities. Previously, she had already been submitted to pulse therapy with corticosteroid by other medical service, not presenting satisfactory control of the myopathic condition. The patient presented electromyography, characteristic of proximal myopathy with signs of membrane instability and muscle biopsy suggesting immune-mediated necrotizing myopathy. Also presented autoantibodies (ANA, anti-DNA, anti-Jo1, ANCA, anti-Ro, anti-La negative) and anti-HMG-CoA reductase positive $(125 \mathrm{mg} / \mathrm{dL})$. Two months after glucocorticoid pulse therapy, presented clinical worsening associated with dysphagia and increase in muscle injury markers, which motivated her hospitalization in our medical service, with intravenous immunoglobulin (IVlg) therapy being administrated for 5 days, in addition to prednisone $60 \mathrm{mg} /$ day, demonstrating a subsequent drop in muscle enzymes and progressive gain of muscle strength with adjuvant physical therapies. Currently she has been accompanied on an outpatient basis with methotrexate.

\section{CONCLUSION}

Myalgia and mild elevation of muscle enzymes are common side effects of statin therapy. Although these symptoms are usually self-limiting, in rare cases the use of statins is associated with an immune-mediated necrotizing myopathy caused by the development of autoantibodies against HMG-CoA reductase. Despite being unusual, IMNM associated with statin is an important cause of muscle weakness to be considered, given its similar characteristics to other inflammatory myopathies, its potentially debilitating consequences and, therefore, the need for early treatment to recover from the condition.

\section{KEYWORDS}

Immune-mediated necrotizing myopathy, Statins, Intravenous immunoglobulin. 